\title{
Understanding the Current Conditions of Tourism Product and Tourism Perceptions in As-Salt City, Jordan
}

\author{
Ali Salem Hyasat ${ }^{1} \&$ Marwan A. Alnahleh ${ }^{2}$ \\ ${ }^{1}$ Faculty of Planning and Management, Al-Balqa Applied University, Jordan \\ ${ }^{2}$ Department of Financial \& Banking Sciences, Jarash University, Amman, Jordan \\ Correspondence: Ali Salem Hyasat, Faculty of Planning and Management, Al-Balqa Applied University, Jordan. \\ E-mail: hyasat@hotmail.co.uk
}

Received: March 31, 2014

Accepted: August 9, 2014 Online Published: November 26, 2014

doi:10.5539/jms.v4n4p147

URL: http://dx.doi.org/10.5539/jms.v4n4p147

\begin{abstract}
This study aimed to understand the current condition of tourism product and tourist perceptions in As-Salt City. Quantitative research methodology has been developed to meet the research aims and objectives. The quantitative technique was used based upon the opinion of tourists who visited Salt in order to understand the current condition of tourism product and tourist perceptions in Salt.

The result revealed that tourists in Salt were younger than expected especially Jordanian ones and the majority of them were females. Period stayed in Salt was mostly less than one day for the highest percentage of tourists especially for non-Jordanians. The most common reason for coming to Salt was because Salt is close to Amman (the capital of Jordan). After visiting As Salt, most of tourists' especially non-Jordanians had a very positive reaction about Salt and recommended it for others, although they faced some difficulties in it such as bad traffic and other some facilities'.
\end{abstract}

Keywords: As-Salt City, National Tourism Strategy, Alkhader church

\section{Introduction}

Jordan is strategically positioned at the convergence of Europe, Asia and Africa, Jordan is a small country. It is around $460 \mathrm{~km}$ in length and by $355 \mathrm{~km}$ in width, a total of about 92,000 sq km (Kennedy, 2004). Jordan is bordered by Syria to the north, Iraq to the northwest, Saudi Arabia to the east and south and Palestine and Israel to the west.

Without significant oil resources and consisting largely of semi-arid plateaux and desert, the service sector (including the tourism industry) has become an important part of Jordan's National Economy (JNE) (Note 1).

Over the past decade, tourism has emerged as one of Jordan's most rapidly growing economic activities, ranking second in terms of foreign exchange earnings (Note 2). This has led to an increase in the level of contribution of this sector to the JNE reaching almost $12 \%$ in the year 2012. According to the Jordan National Tourism Strategy (JNTS) 2011-2015, about 40,000 people were directly employed in the tourism sector. It is believed that employment generated by the indirect economic impact of tourism is several times greater than the direct employment generated. The Government of Jordan, through the execution of its Executive Development Program 2011-2013 (EDP), is trying to strengthen the competitiveness of the tourism industry by developing and diversifying tourism products, improving the quality of tourism services, exploring new markets, and increasing tourism-related investment. MOTA is working on comprehensive tourism development through public-private partnership in order to increase tourism revenues from JD 2.66 billion in 2009 to the JD 4.2 billion in 2015 targeted in the JNTS (JNTS, 2010).

As Salt City is unlike other tourist sites in Jordan, which are predominantly archaeological; As Salt City is characterized by historical buildings from the late 19th and early 20th centuries. The City is expected to develop a new type of tourism site, where tourists can experience the lifestyle and culture of the local community. As individual or small group tourism has been the most rapidly growing area of international tourism, developing As Salt City, therefore, it will be important for diversifying tourism products in Jordan. Once successful, the model developed in As Salt City can be replicated in other cities in Jordan with a historical townscape and original culture, and thus contribute to increasing the competitiveness of Jordan in the global tourism market (INJICA, 
2012).

However, a major plan by the MOTA was established to tap into the rich heritage of Salt and transform it into an attractive tourism destination for local, Arab and international tourists. The Salt City Trail Development Plan defines MOTA efforts to put Salt on the tourist map and outlines supporting initiatives that have been or will be implemented by donor agencies working in the area. These included the World Bank-funded Third Tourism Development Project, JICA and USAID. The Salt City Trail was a part of a national initiative to develop tourism trails around Jordan, of which Salt will be the model for developing city trails (MOTA, 2009).

The launch of As Salt City Trail plan came after extensive planning and assessments in Salt, which MOTA conducted in close coordination with the local community, including decision makers, associations, leaders, families, women, and business owners. The planning, which was conducted with support from the USAID, helped to determine the potential and requirements in order to meet the needs of the community and best serve tourism, (MOTA, 2009).

As previously stated, recently MOTA, USAID and JICA have been working on tourism development and boost in As-Salt City. The ministry has been working to renovate and conserve traditional buildings such as mosques and the houses of wealthy merchants, in order to give tourists a taste of the Kingdom's urban heritage and how life was at the turn of the 20th century when the foundations of the country were being built. The ministry has been also working with the USAID to promote local investment in the area, encouraging As-Saltis to develop shops, cafés, restaurants or other ventures that could benefit from the Kingdom's growing tourism sector, (MOTA, 2009).

According to the (World Bank and MOTA, 2005) report, in general, the residents were aware of their city's importance in Jordan as well as its distinctive old buildings and streets and they also cared very much for the preservation of its heritage and archaeological sites. Given this, there was a widespread feeling of resentment among residents as for the fact that Salt has been left out from the tourist map of Jordan, and blame for this is laid on Ministry of Tourism's shoulders. Thus, currently there was no significant number of tourists coming to Salt. Therefore, the supply of tourism related facilities was poor. Moreover,as for tourism as economic activity, there was a prevalent lack of awareness about its benefits and some expect that some problems may arise among the residents as results of envy and exclusion from activities seen to be important in the City.

In conclusion, there was still some lack in research and literature in general that discusses all aspects of tourism in Salt, especially tourism product and tourist perceptions in As-Salt and its contribution to the Jordanian collective tourism business, therefore, this study was prepared to fill this gap.

\subsection{Study Amis and Objectives}

The main aim of this survey was to understand the current conditions of tourism product and tourist perceptions in As Salt City through the following objectives:-

1) To identify the profile of tourist's and their visits overview.

2) To classify the type of activities and the amount of expenditure.

3) To identify the perception of Salt (satisfaction and problems).

\subsection{Study Design and Methods}

\subsubsection{Study Methodology}

This study was based on applying quantitative research methodology. A quantitative method was used to meet the main aim and objectives for the survey based on developing a questionnaire that targeted tourists who visited Salt, in order to have a general understanding of their opinion about tourism in Salt and their state of participation.

\subsubsection{Data Collection Techniques}

In order to meet the main aim and objectives for the survey a quantitative technique was used by designing a questionnaire. Questions were asked to tourists who visited As Salt about their visits, activities and amount of expenditure, whether their visit was arranged by a travel agency or individually carried out and their perception of Salt, satisfaction and problems. By using a random sample technique the researcher disrupted questionnaires to Jordanian and non-Jordanian tourists, (131) out of those questionnaires have been filled up by tourists and collected by the researcher. However, the researcher found that there were only (107) questionnaires filled up properly in a reliable manner which enabled the researcher to conduct the research. Moreover, the literature review, statistical data and all documents about tourists and tourism in As Salt have been collected by the 
researcher.

\subsubsection{Research Sampling}

The list of sample for the survey was based on the random sampling technique in order to meet the main aim and objectives of the survey. The investigation of the current condition of tourists in Salt has been conducted through distributing (175) questionnaires to Jordanian and non-Jordanian tourists in As-Salt City. In order to insure that tourists will fill up the questionnaires correctly, the questionnaire was distributed in three main heritage sites, Al-Khader`s Church, HOSM and the Archeological's Museum, which were expected to be seen by most of tourists who visited Salt.

\subsubsection{Data Analysis}

Data was analyzed using a review of all discussion from the answers questionnaire for the survey. The data was reflected on answering the fundamental questions of the research for the questionnaire, and it was analyzed to achieve the aim and objectives of this study. After analyzed the data collected for the survey, this study produced a frameworkof tourist's participation in As Salt City.

The SPSS software was used to conduct analyses for the survey. However, SPSS Program is a software package used for statistical analysis. It is now officially named "IBM SPSS Statistics". (http://en.wikipedia.org/wiki/SPSS)

SPSS (originally, Statistical Package for the Social Sciences, later modified to read Statistical Product and Service Solutions) was released in its first version in 1968 after being developed by Norman H. Nie, Dale H. Bent and C. Hadlai Hull. SPSS is among the most widely used programs for statistical analysis in social science. It is used by most of the social sciences researchers, such as market researchers, health researchers, survey companies, government, education researchers, marketing organizations and so on. (http://en.wikipedia.org/wiki/SPSS).

Some important factors such as profile of the tourist, overview of the visit, types of activities, and any arrangements by travel agencies have been examined. The survey was analyzed through cross sectioning the nationality of the tourists with all answers of the questions in the questionnaire. Jordanian tourists could have different points of view than non-Jordanian ones. Therefore, the cross tabulation technique was performed.

\section{Data Analysis}

To have a better understanding of the current condition of tourists in Salt, this part of the study contained cross tabulation analysis for the whole questionnaire separately according to the tourists' nationality (Jordanian or non-Jordanian).

\subsection{Cross Tabulation}

\subsubsection{Age}

Table 1. Cross tabulation for nationality with age

\begin{tabular}{lllllll}
\hline & less than 18 & 18 to 30 & 31 to 40 & 41 to 50 & 51 to 60 & more than 61 \\
\hline Jordanian & 16 & 7 & 0 & 4 & 2 & 0 \\
non-Jordanian & 8 & 22 & 13 & 17 & 12 & 8 \\
\hline
\end{tabular}

As can be concluded from table 1, the majority of Jordanian tourists were less than (18) years of age while there were no Jordanian tourists between (31 and 40) or more than (61) years old. On the other hand, (24\%) of Jordanian tourists were between (18 and 30) years old. (14\%) and (7\%) were in the age of (41 to 50) and (51 to 60) respectively.

Meanwhile, as can be seen in the above table 1 that non-Jordanian tourists have ranged within all categories of ages, but they were slightly more clustered in the age between (18 to 30 ) years old (28\%). In other words, the average of tourism ages was younger in the case of Jordanian tourists compared to the non-Jordanians. 


\subsubsection{Sex}

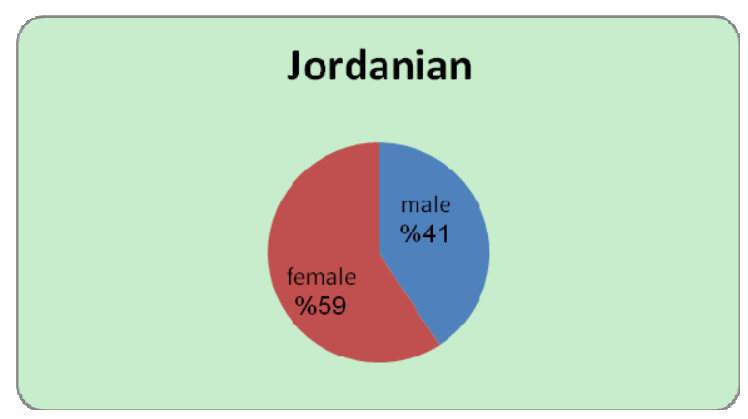

Figure 1. Cross tabulation analysis for nationality with sex of Jordanian tourists

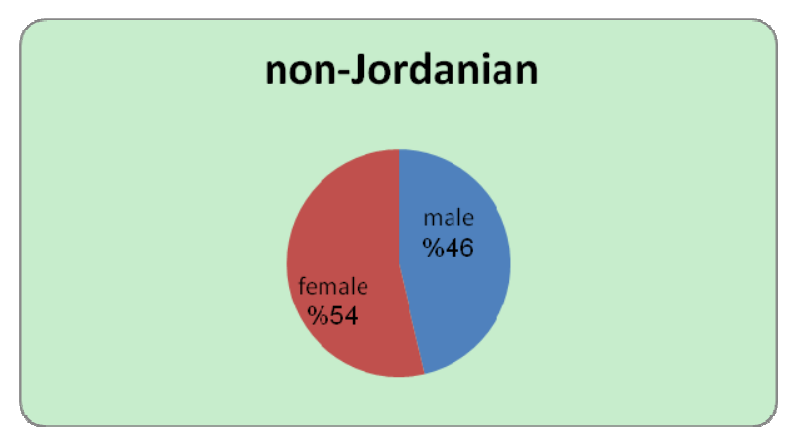

Figure 2. Cross tabulation analysis for nationality with sex of non-Jordanian tourists

The above figures 1 and 2 show that the result of both sides (Jordanian and non-Jordanian) tourists revealed that female tourists have exceeded male tourists in terms of numbers, where (58\%) of Jordanian tourists were females and they were (54\%) in the case of non-Jordanians.

\subsubsection{Time Spent in Salt}

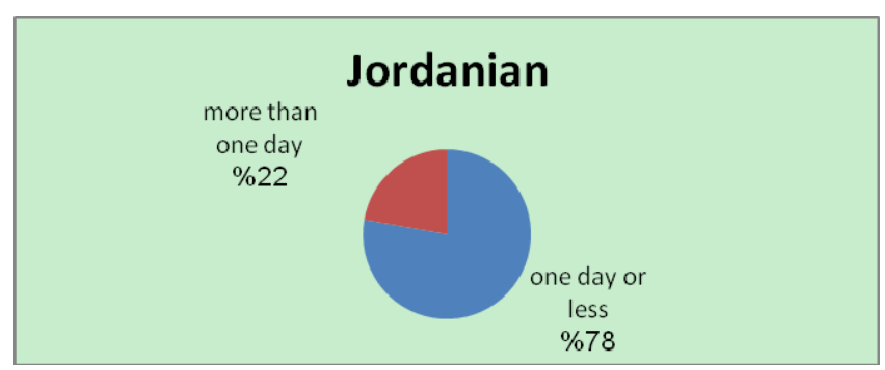

Figure 3. Cross tabulation for nationality with time spent in Salt for Jordanian tourists

As can be seen in figure 3, the vast majority of Jordanian tourists did not stay more than one day in Salt with $(78 \%)$, this is normal because they could drive home the same day they arrived to Salt.

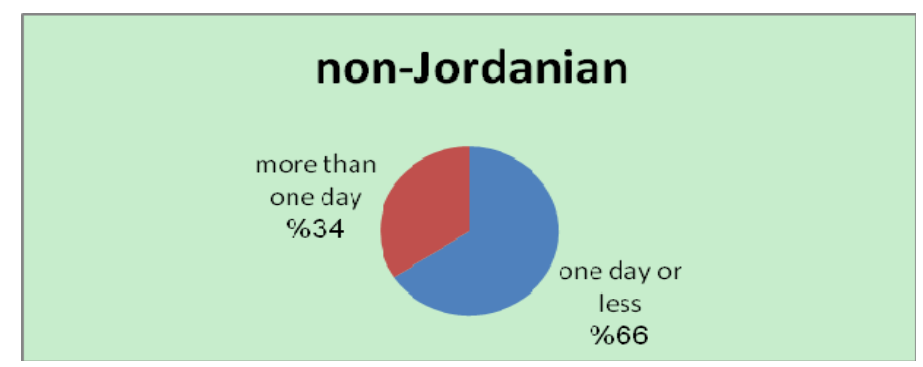

Figure 4. Cross tabulation for nationality with time spent in Salt for non-Jordanian tourists 
Similarly, figure 4 revealed that non-Jordanian tourists mostly visited Salt and stayed less than one day and the percentage was $(66 \%)$ non-Jordanians, this was mainly due to the no availability of hotels to accommodate them. On the other hand, significant shares $(34 \%)$ of non-Jordanian tourists have managed to stay more than one day in Salt.

\subsubsection{Destination to Reach Salt}

Table 2. Cross tabulation for nationality with destination to reach Salt

\begin{tabular}{llllll}
\hline & Amman & Jerash & Dead Sea & Madaba \& Mount Nebo & Others \\
\hline Jordanian & 19 & 1 & 3 & 1 & 3 \\
non-Jordanian & 50 & 6 & 9 & 9 & 6 \\
\hline
\end{tabular}

As shown in above table, the vast majority of Jordanian and non-Jordanian tourists came from Amman to reach Salt but this percentage was higher for Jordanian tourists $(70 \%)$ compared to their non-Jordanian counterparts $(62 \%)$, and on there was no significant difference between Jordanian and non-Jordanian tourists in this term for other destinations shown in the above table.

\subsubsection{Who Came with the Tourist?}

Table 3. Cross tabulation analysis for nationality and person came with the tourist

\begin{tabular}{llllll}
\hline & husband/wife & a friend & family member & colleague & nobody \\
\hline Jordanian & 19 & 1 & 3 & 1 & 3 \\
non-Jordanian & 50 & 6 & 9 & 9 & 6 \\
\hline
\end{tabular}

Once again, cross tabulation analysis as shown in the above table revealed that Jordanian and non-Jordanian tourists come to Salt accompanied with husband or wife in most cases especially and surprisingly for Jordanians where this percentage was $(70 \%)$ percent in their case, this was surprising because as mentioned earlier (55\%) of Jordanian tourists were less than (18) years old. However, the only way to explain this because those under (18) years old were mostly students came to Salt with school arranged tours and they were mixed (males and females), and most of them consider their boy/girlfriends as their husband/wife, therefore, their answers in this regard were not reliable.

\subsubsection{Method of Transportation}

Table 4. Cross tabulation analysis for nationality with method of transportation

\begin{tabular}{llllll}
\hline & public transportation & private car & rented care & taxi & tour bus \\
\hline Jordanian & 2 & 16 & 5 & 3 & 1 \\
non-Jordanian & 18 & 27 & 16 & 8 & 10 \\
\hline
\end{tabular}

As canbe concluded from above table $(78 \%)$ of Jordanian tourists have driven either their own cars $(59 \%)$ or have used rented cars (19\%) as they were familiar with driving in Jordan and Salt in particular. On the other hand, $(11 \%)$ of them have used taxi and collectively (11\%) used public transportation (7\%) and tour buses (4\%).

Table 4 shows some differences in the attitude of both tourists categories towards method of transportation used in Salt. It also shows that non-Jordanian tourists tended to use public transportation and tour buses more often than Jordanians with $(23 \%)$ and $(13 \%)$ respectively. In regard to the use of tour buses, the difference was mainly because non-Jordanian tourists usually come to Salt by arranged groups. For using private and rented cars non-Jordanian tourists used private cars less than Jordanians with (34\%) but they used rented cars almost same as Jordanians with $(20 \%)$. 


\subsubsection{Purpose of Visit}

Table 5. Cross tabulation analysis for nationality with purpose of visit

\begin{tabular}{llllll}
\hline & sightseeing & seeing family or relatives & seeing friends & business & other \\
\hline Jordanian & 2 & 7 & 3 & 1 & 13 \\
non-Jordanian & 22 & 19 & 9 & 6 & 22 \\
\hline
\end{tabular}

The above table 5 shows that half of the Jordanian tourists came to Salt for other reasons such as religious reasons for example, Jordanian Christians come to pray in Alkhader church, another reason is that they might come for sports or power walking. Collectively (38\%) of Jordanian tourists come to Salt for visiting family or relative $(27 \%)$ or friends $(11 \%)$ as there are many of originally Salti people who are living in other cities. On the other hand, only $(8 \%)$ of them come for sightseeing or business ( $4 \%)$.

Reasons for coming to Salt differed for non-Jordanian tourists from Jordanians. The above table shows that there was high percentage of non-Jordanians who came to Salt for sightseeing (28\%) or for other reasons such as religious reasons.

\subsubsection{Decision to Visit Salt}

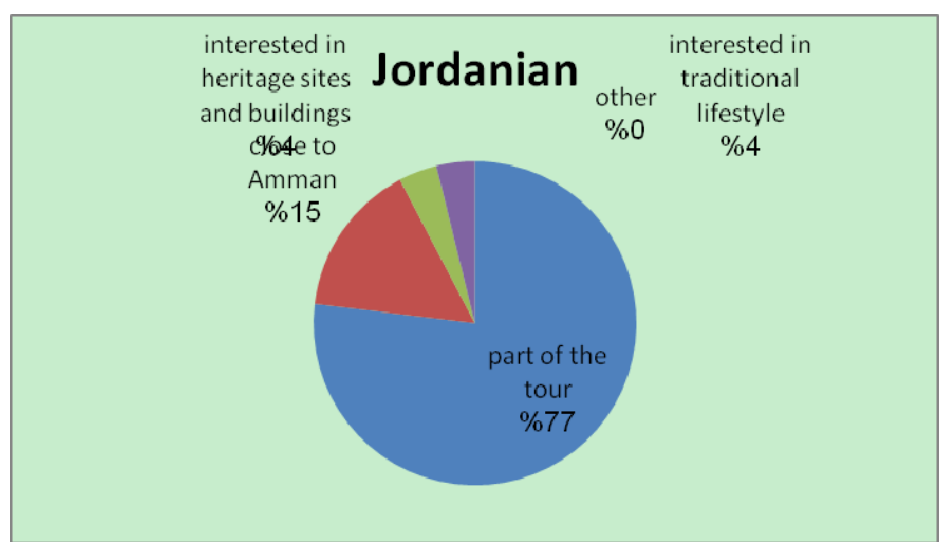

Figure 5. Cross tabulation analysis for Jordanian tourists and their decision to visit Salt

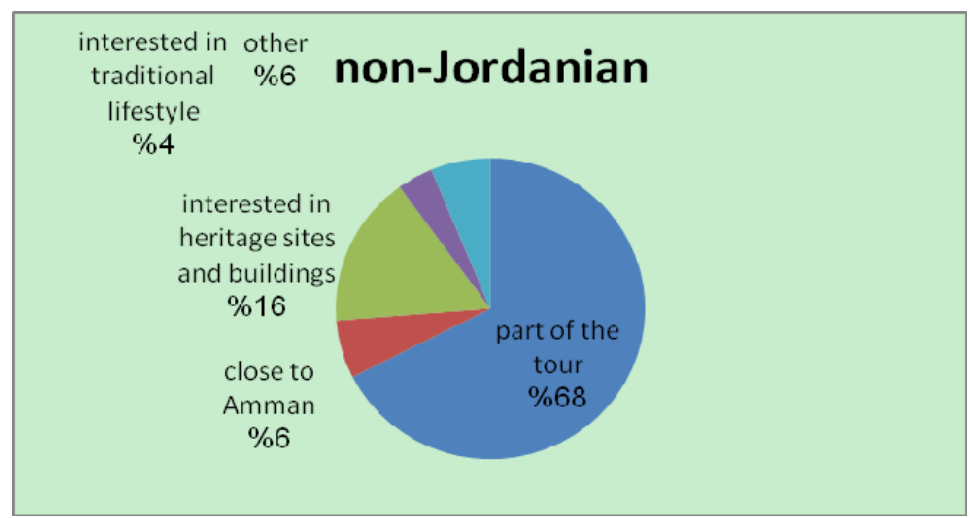

Figure 6. Cross tabulation analysis for non-Jordanian tourists and their decision to visit Salt

As shown in the above figures 5 and 6 , the majority of both types of tourists only came to Salt because it was a part of their tour. However, the analysis revealed that there were a significant percentage of non-Jordanians who came because they were interested in heritage sites and buildings, $(15 \%)$ of Jordanian tourists came to Salt only because it was close to Amman, while this percentage was only (6\%) for non-Jordanians. 


\subsubsection{The Way Tourists Knew about Salt}

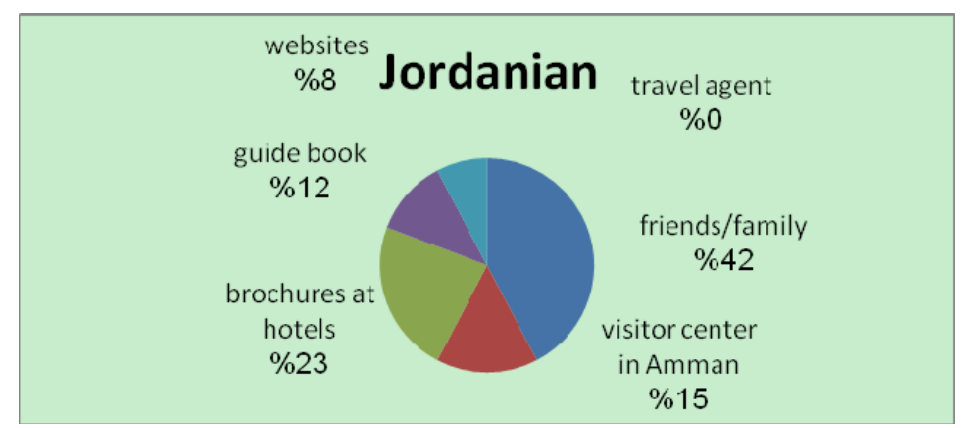

Figure 7. Cross tabulation analysis for Jordanians and the way they knew about Salt

According to the figure 7, no Jordanian tourist knew about Salt by a travel agent while significantly (42\%) of them knew about Salt by family and friends. However, the percentage of Jordanian tourists that knew about Salt by brochures at hotels or guide books was collectively (35\%) and this is also significant percentage, while only $(8 \%)$ of them knew about it by websites.

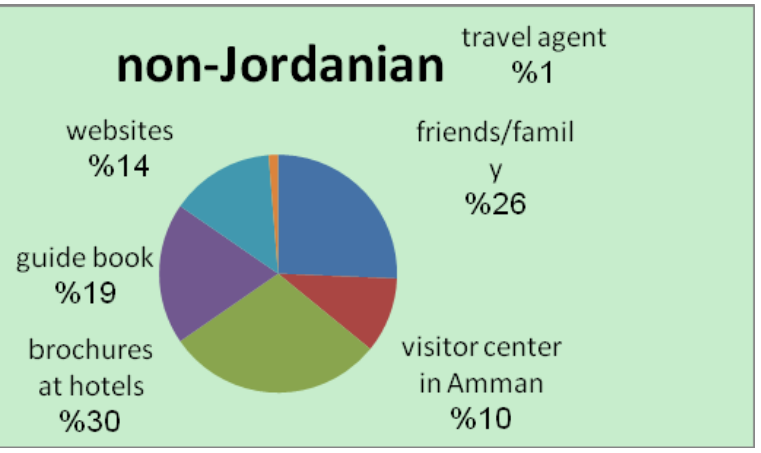

Figure 8. Cross tabulation analysis for Jordanians and the way they knew about Salt

It can be seen in figure 8 that brochures at hotels were effective and efficient with non-Jordanian, many tourists of both types knew about Salt through them but they were more from non-Jordanians. Meanwhile, guide books websites, and visitor center in Amman were less effective but they were still introducing Salt to some non-Jordanian tourists with $(19 \%),(14 \%)$, and (10\%) respectively. However, significant percentage (26\%) of non-Jordanian tourists knew about Salt by friends or family.

\subsubsection{Activities Done by Tourists}

Table 6. Cross tabulation for nationality with activities

\begin{tabular}{lll}
\hline & Jordanian & non-Jordanian \\
\hline visit old Salt museum & 12 & 29 \\
visit archaeological museum & 10 & 20 \\
visit Souk (Hammam street) & 11 & 24 \\
visit traditional buildings & 7 & 19 \\
visit family/relatives/ friend's house & 5 & 4 \\
eat local food & 4 & 12 \\
communicate with local people & 3 & 12 \\
have tea or coffee at cafes & 2 & 10 \\
participate in events and festivals & 4 & 1 \\
buy souvenirs and gifts & 3 & 2 \\
Others & 3 & 5 \\
\hline
\end{tabular}


As shown in table 6, visiting old Salt museum, Hammam street, archaeological museum, and traditional buildings were the most visited by Jordanian tourists with $(19 \%),(17 \%),(15 \%)$, and (11\%) respectively.

Table 6, also shows that activities done by non-Jordanian tourists in salt were similar to those done by Jordanians. However, it was expected that Jordanian tourists were more than their non-Jordanian peers in terms of visiting family/relatives/friends, because they are more expected to have family/relatives/friends in Salt which is a city in Jordan.

\subsubsection{Arrangement by a Travel Agent}

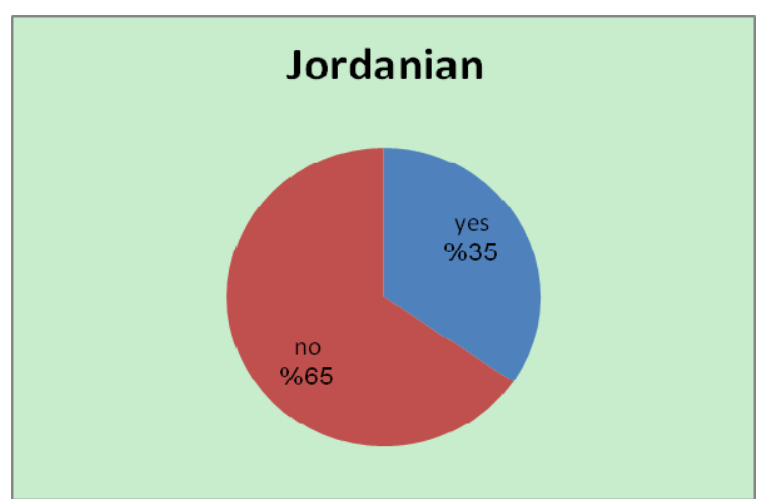

Figure 9. Cross tabulation for Jordanians with arrangement by travel agency

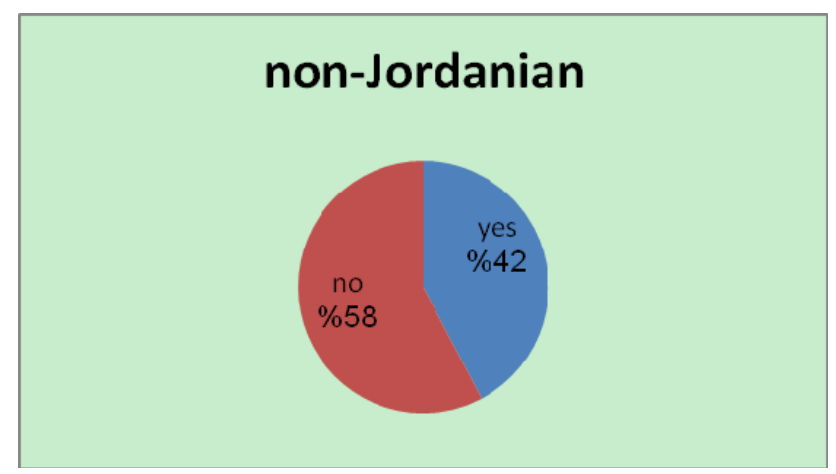

Figure 10. Cross tabulation for non-Jordanians with arrangement by travel agency

As shown in the above figures 9 and 10, the share of tourists coming to Salt according to arrangement by a travel agency was higher for non-Jordanian tourists because non-Jordanians tourists tended to have arrangements more than Jordanians. In both cases, less than half of the tourists their visit to Salt was arranged by a travel agent.

\subsubsection{Including other Destinations in the Package}

Table 7. Cross tabulation analysis for nationality with including other destinations

\begin{tabular}{lll}
\hline & yes & no \\
\hline Jordanian & 9 & 0 \\
non-Jordanian & 32 & 1 \\
\hline
\end{tabular}

The result of this analysis as shown in table 7 is clear and straight forward, it says that tour packages of Jordanian tourists have included other destinations with (100\%), this might indicate that Salt is not yet considered as a main tourism destination for Jordanian tourists.

According to table 7, only (3\%) (1) person of non-Jordanian tourists did not included other destinations in the tour package, which is a very small number that has the meaning that non-Jordanian tourists do not consider Salt 
as a main tourism destination.

2.1.13 Places Included in the Package

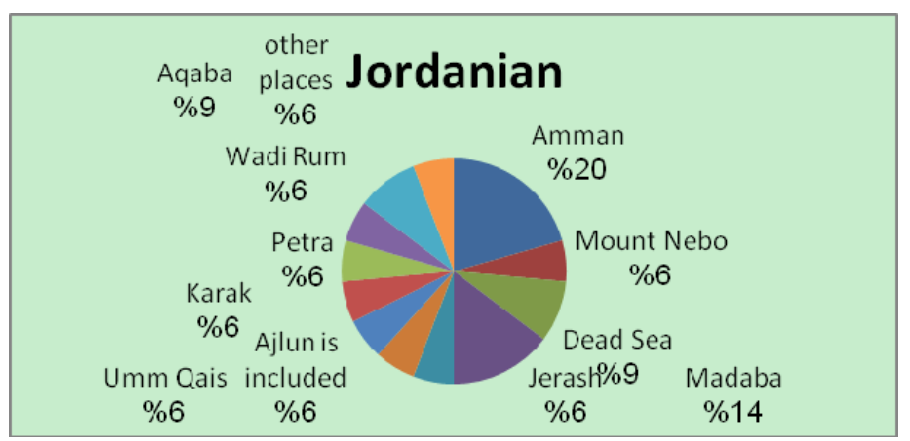

Figure 11. Cross tabulation analysis for Jordanian tourists and places in the arrangement

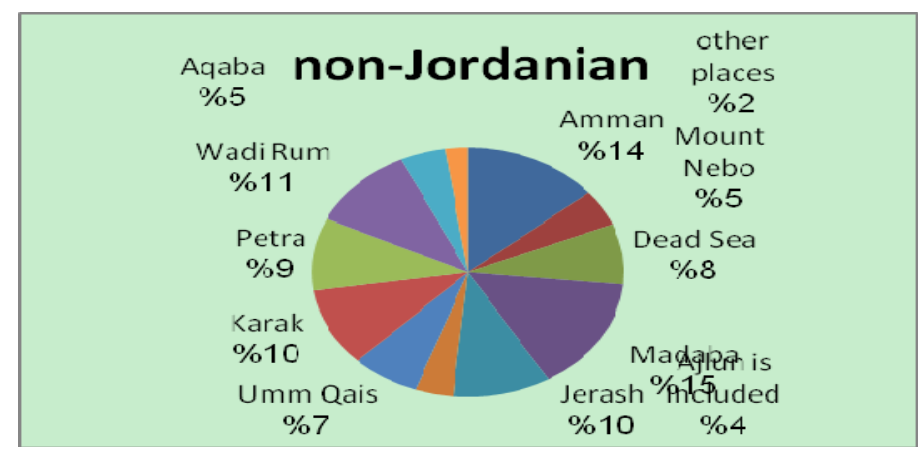

Figure 12. Cross tabulation analysis for Jordanian tourists and places in the arrangement

Figure 11 and 12 show that closer destinations to Salt such as Amman and Madaba were more included in the tour packages that included salt especially in the cases of Jordanian tourists. On the other hand, the percentage of non-Jordanian tourists that came from far cities in Jordan was slightly higher.

2.1.14 Services Included in the Package

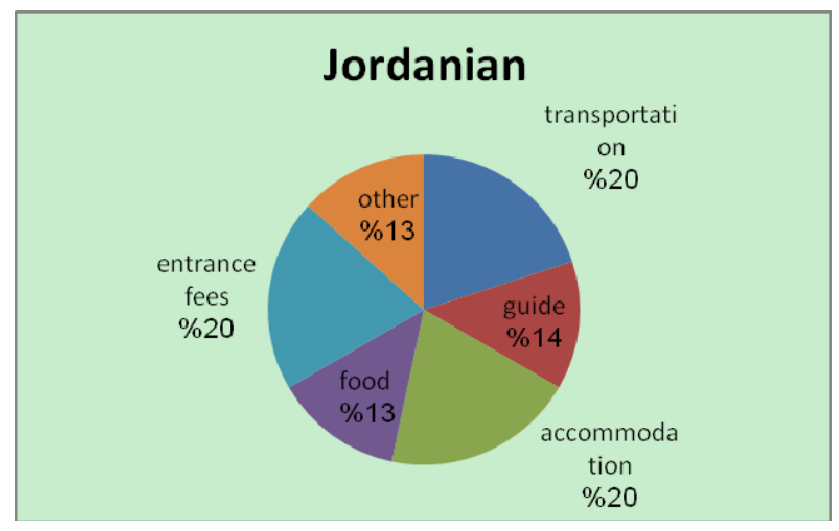

Figure 13. Cross tabulation analysis for Jordanians with services in the arrangement 


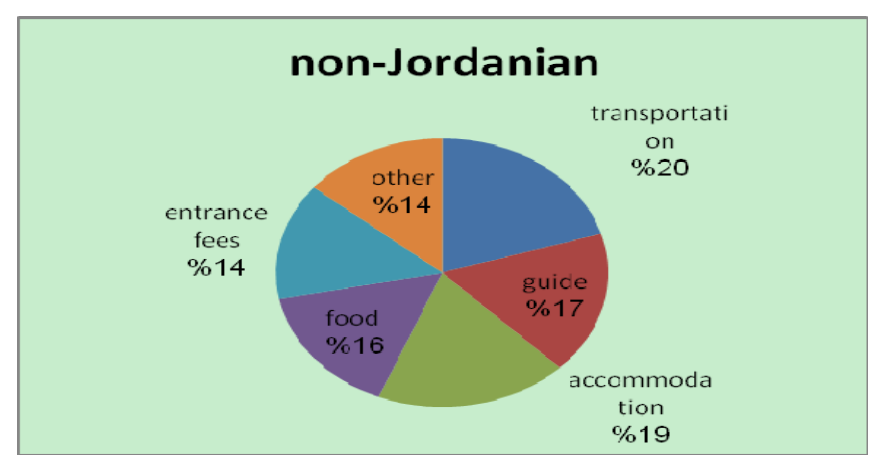

Figure 14. Cross tabulation analysis for Jordanians with services in the arrangement

The analyses represented by figures 13 and 14 show that Jordanian tourists in Salt did not take significantly different packages from those are taken by non-Jordanian tourists in Salt in terms of services included in it.

\subsubsection{Expectations}

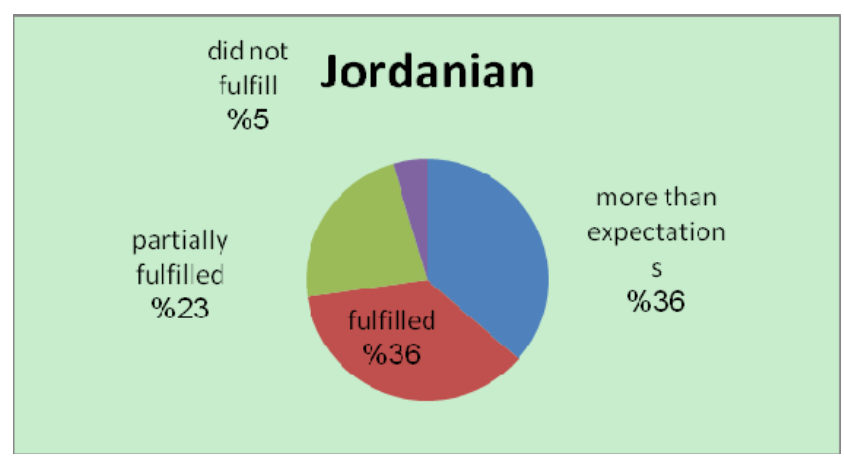

Figure 15. Cross tabulation for Jordanian tourists with expectations

According to the above figure 15, a significant share of Jordanian tourist had a positive expectation fulfillment by either finding Salt fulfilling their expectations or more than expectations by (36\%) for each, which gives the indication that Salt has a bright future as a tourism destination to be put on the tourism map of Jordan. Not to mention that (23\%) of Jordanian tourists those have found Salt partially fulfilling their expectations. Only (5\%) of them did not fulfill their expectations when they visited Salt.

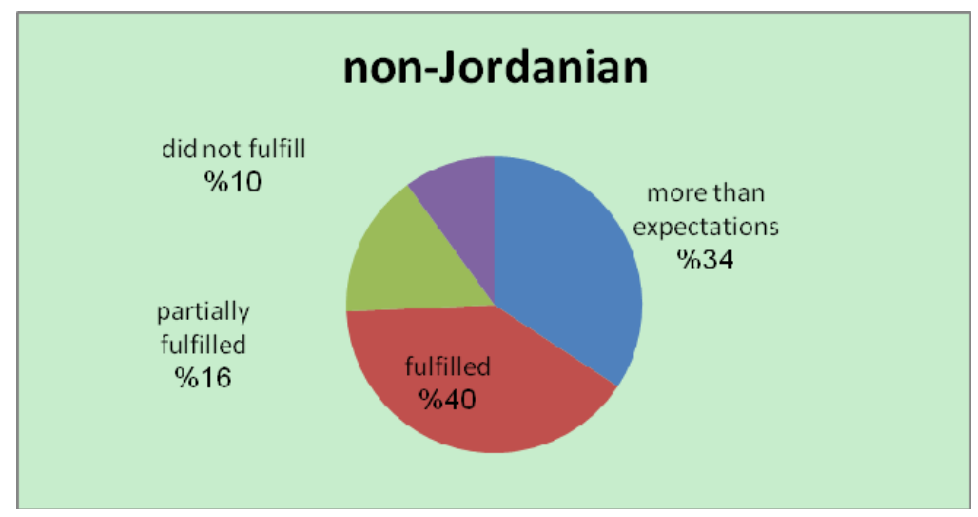

Figure 16. Cross tabulation for non-Jordanian tourists with expectations 
The above figure 16 shows that similarly, non-Jordanian tourists in Salt were even more positive in terms of their opinions about Salt based on their previous expectations. This was because of that international tourists did not have enough information about Salt compared with Jordanian tourists. However, the significant difference between Jordanian and non-Jordanian tourists in this term comes from tourist who partially fulfilled their expectations and did not fulfill them by (16\%) and (10\%) respectively for non-Jordanians.

2.1.16 Difficulties in Salt

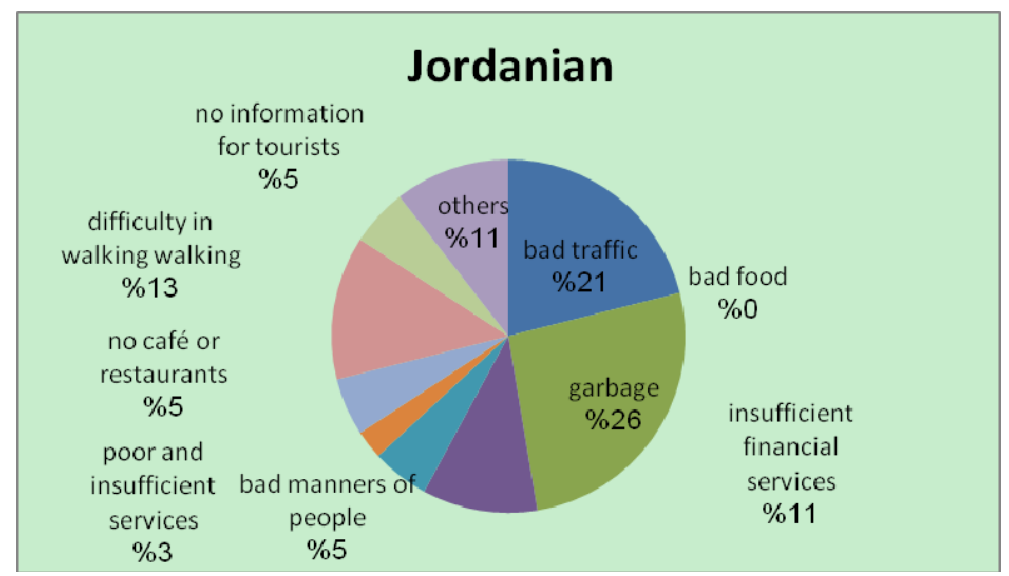

Figure 17. Cross tabulation analysis for Jordanian tourists with difficulties in Salt

As shown in the above figure 17, Jordanian tourists have mostly complained from the garbage issue accounting for $(26 \%)$ and bad traffic accounting for $(21 \%)$. Moreover, (13\%) of Jordanians faced difficulty in walking through Salt street and tough stairs, while (11\%) of them faced other difficulties such as bad smells in the street and this also caused by the garbage.

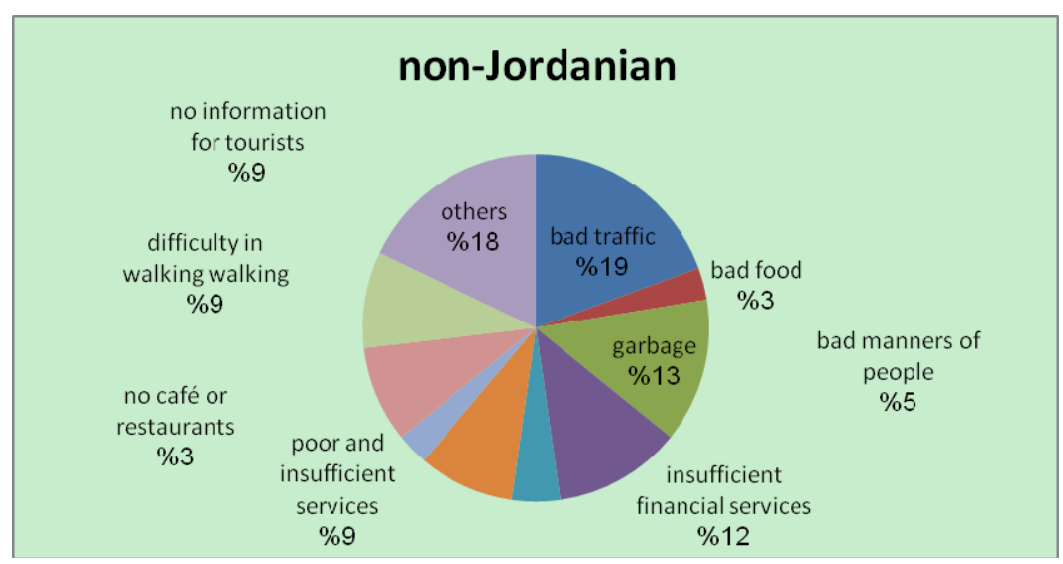

Figure 18. Cross tabulation analysis for non-Jordanian tourists with difficulties in Salt

As can be seen in the above figure 18, non-Jordanian tourists faced the difficulty of bad traffic even more than the Jordanian once with (19\%). Regarding facing other difficulties, (18\%) of non-Jordanian tourists found that smells and whether as difficulties in Salt. However, non-Jordanian tourists who faced the difficulty of garbage were less than their Jordanian counterparts with (13\%). 


\subsubsection{Recommendation}

Table 8. Cross tabulation analysis for nationality with recommendations

\begin{tabular}{llllll}
\hline & definitely yes & perhaps & not sure & no & never \\
\hline Jordanian & 16 & 2 & 2 & 1 & 2 \\
non-Jordanian & 54 & 6 & 3 & 5 & 8 \\
\hline
\end{tabular}

As shown in the above table, Jordanian and non-Jordanian tourists were mostly positive and definitely recommended Salt with $(69 \%)$ and $(71 \%)$ respectively.

2.1.18 Events Wished to Have in Salt by Tourists

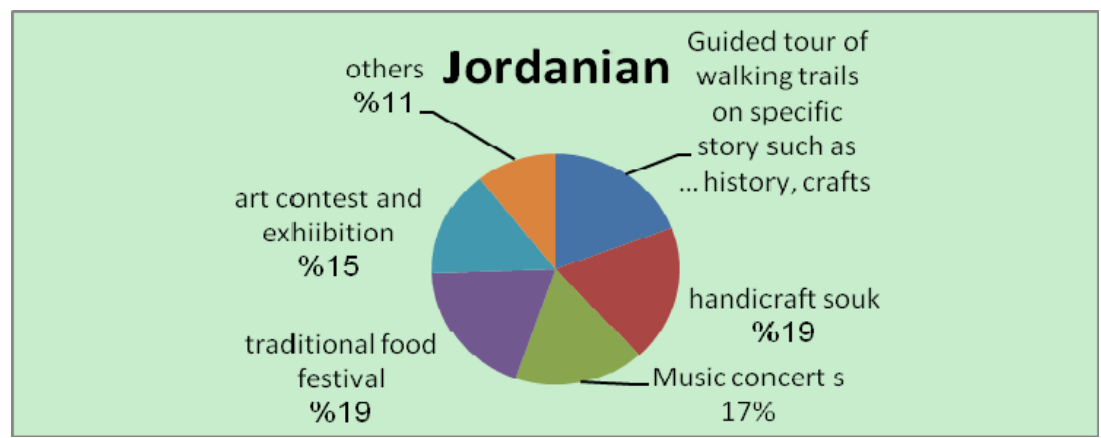

Figure 19. Cross tabulation for Jordanian tourists with events wished to have in Salt

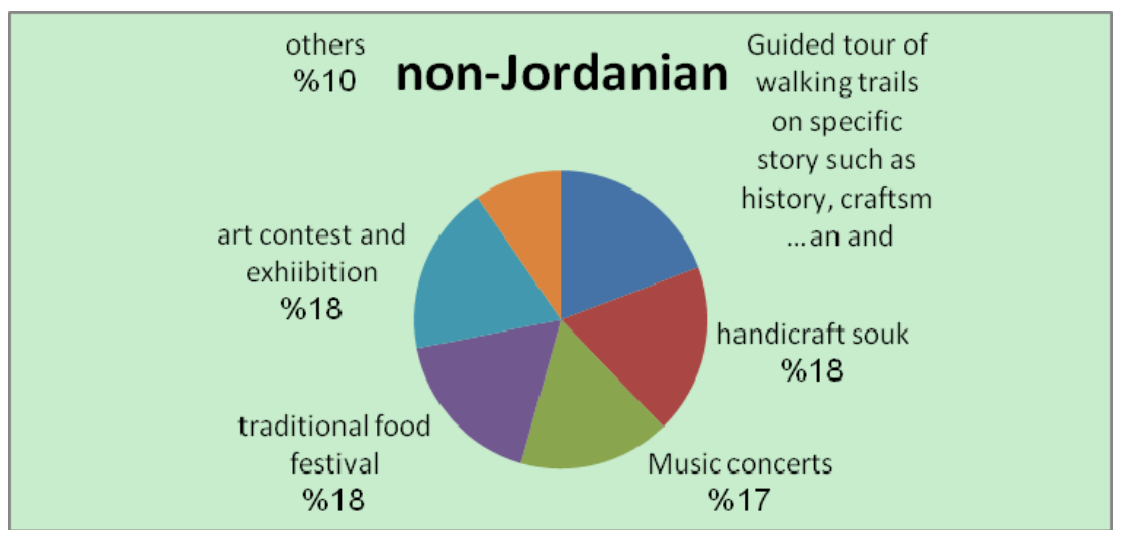

Figure 20. Cross tabulation for non-Jordanian tourists with events wished to have in Salt

As seen in the above figures 19 and 20, tourists from both types wished almost all events in similar degrees. However, non-Jordanian tourists were more slightly interested in art contests and exhibitions than Jordanians.

\section{Conclusions}

As mentioned earlier, the survey was conducted to understand the current conditions of tourism product and tourist perceptions in As Salt City by using a quantitative technique, mainly a questionnaire. In the following sections are the conclusions of the survey in association with its aims and objectives.

The main aim for the survey was to understand the current conditions of tourism product and tourist perceptions in As Salt City through the following objectives:-

1) To identify the profile of tourists and their visit overview.

2) To classify the type of activities.

3) To identify the perception of Salt (satisfaction and problems).

The following sections present the outcomes of the above aim objectives: 


\subsection{Identifying Profile of Tourists and Overview of Visit}

As previously mentioned, Jordanian tourists represented only $(25 \%)$ of tourists came to Salt because Salt was more promoted for foreign tourists than local tourists in Jordan, forgetting that Jordanian tourists can contribute to the development of tourism sector in Salt as well as the non-Jordanians. A significant percentage of Jordanian tourists were less than (18) years of age and this could be due to tours organized by schools. However, the average age for tourists was younger than expected which could give an indication that Salt was getting more famous and recognized for young people in general and for travel agencies in particular.

It was concluded through the analysis that Salt is highly visited by both genders in various ages, giving an indication that tourists were diversified because they mainly felt comfortable being in Salt, and it was recommended by them to be visit by others.

The study also revealed that tourists only came for a short visit by not considering Salt as their main tourism destination, therefore, most of them did not stay in Salt more than one day. On the other hand, there were a significant percentage of non-Jordanian tourists who stayed more than one day in Salt.

Nevertheless, because Amman is very close to Salt and, therefore, most of tour arrangements include Amman, this came in line with the fact that tourist did not usually spend more than one day in Salt, considering that it usually came as a part of the tour. It could be also concluded that Salt was a family tourism destination as most of tourists came to Salt along with their husband/wife, which gave an indication that tourists feel safe and comfortable coming to Salt.

It was noticed that the vast majority of Jordanian and surprisingly non-Jordanian tourists were able to use their own cars or rented cars in Salt, but the public transportation sector was obviously not meeting the needs of Jordanian tourists in particular. Although they came to Salt mostly because it was a part of their tour, non-Jordanian tourists were very interested in sightseeing and religious destinations when they visited Salt, while Jordanians mainly visited Salt for visiting family or friends and for sports such as running and power walking to benefit from the tough geography of Salt.

\subsection{Identifying Types of Activities for Tourists in Salt}

In terms of this objective the results revealed that non-Jordanian tourists were more interested in Salt's traditional life and museums than Jordanian ones. Although most of tourists claimed that they came to Salt only because it was a part of their tours, less than half of them visited Salt based on an arrangement by travel agencies. It also could be said that all tourists in Salt did not come only to Salt, there were other destinations mostly were included such as Amman, Madaba, and the Dead Sea.

\subsection{Identifying Perception of Tourists (Satisfaction and Problems)}

The outcomes revealed that tourists were generally satisfied during their visit to As-Salt especially non-Jordanians, and this was mainly because local people in Salt were starting to understand the idea of their city being an important tourism destination and they were giving better services and communication with tourists, therefore, tourists strongly recommended Salt for others. However, the issues of garbage and bad traffic were annoying tourists as well as local people, causing bad smells in the narrow streets making it hard to tolerate for tourists.

\section{Recommendation and Suggestion}

In light with the study findings, a set of recommendations and suggestions could be drawn for future considerations and further research.

- It is strongly recommended that tourists who visit Salt should be provided with a map that includes all attractive tourism areas in Salt and provide them with sign boards in English. In this study the researcher found that tourists had a lake of knowledge about tourist's attraction sits in Salt. This can be achieved by providing all important sites in Salt with brochures and maps which guide the tourist to those attractive sits.

- Another important issue, more guides who can explain to tourists the background of Salt and its attractive sites should be available. However, there is a need for training tour guides in order for them to guide tourist in Salt.

- Most of tourists who visited Salt complained about the transportations and parking. Therefore, there is a need for local institutions to overcome this problem by facilitating accesses to the important tourism attractions areas. Moreover, these institutions should give more attention to the cleanliness issue in Salt. 
- $\quad$ The MOTA should provide more traditional antiques and evidences in the museums both (archeological and historical), and encourage the private sector to establish more café, restaurants and so on in Salt. Furthermore, the relative intuitions should control prices, as tourists complained the manipulation of prices especially with tourists using their ignorance of prices.

- $\quad$ The study revealed that there were no sufficient accommodations for tourists in order for them to stay more than one day and increase their expenditure in Salt making it a major tourism destination for tourists; it is recommended to encourage the private sector to establish hotels in Salt.

\section{References}

AL-DARBEH, N. (2010). Assessment of the Community Participation in Tourism Development Projects of Cultural Heritage Sites: The Old City of al-Salt as a Case Study.

ALhammad, F. (2011). Residents toward tourism development in al salt city Jordan.

ALTai, M. (2004). Archeological Monuments in the Hashemite Kingdome of Jordan, Ministry of Tourism, Amman, Jordan.

Daoud, G. (1994). Salt and its Neighborhood during the period (1864 - 1921), Business Bank Publication Series, Amman, Jordan.

IRJICA. (2012). Sustainable Community Tourism Development Project in As-Salt City, Inception Report, JICA.

JDS. (2011). Jordan Department of Statistics, Annual Report.

JNTS. (2010). National Strategy for Toruism Handcraft Development in Jordan, Amman - Jordan.

JNTS. (2011). Jordan National Tourism Strategy.

KENNEDY, D. B. (2004). Ancient Jordan from the Air, London, The Council for British Research in the Levant the British Academy.

Khraisat, M. A. Q. (1997). Studies in History of Ess-Salt, Publications of the Ministry of Culture, Amman, Jordan.

MOTA, W. B. (2005). Civic Engagement to Improve Development Effectiveness in the Europe and Central Asia Region -The Role of the World Bank. Environmentally and Socially Sustainable Development Unit, Europe and Central Asia Region.

MOTA. (2011). Statistics. Ministry of Tourism and Antiquities.

Tarawneh, M. S. (1992). The History of the Region of Balqa, Ma'an and al-Karak (1864-1918), Publications of the Ministry of Culture, Amman, Jordan .

UNESCO. (2008). World Heritage Tentative List, United Nations - 1992-2010 UNESCO World Heritage Centre, v3.0, Updated 18 Jan 2010. Retrieved from http://whc.unesco.org/en/tentativelists/state=jo

USAID. (2009). Filed Report (Salt Rapid Appraisal) Conducted Through Needs Assessment Methodology Through Participation; Assessment of Tourism Sector and the Tourism Economic Potentials with Local Community in Salt.

\section{Notes}

Note 1 . The serves sector contributes almost $70 \%$ of the GNP.

Note 2. The main foreign exchange is the Jordanian overseas remittances, especially those who work in the Gulf States. They provide Jordan around US\$ 3 billion each year.

\section{Copyrights}

Copyright for this article is retained by the author(s), with first publication rights granted to the journal.

This is an open-access article distributed under the terms and conditions of the Creative Commons Attribution license (http://creativecommons.org/licenses/by/3.0/). 